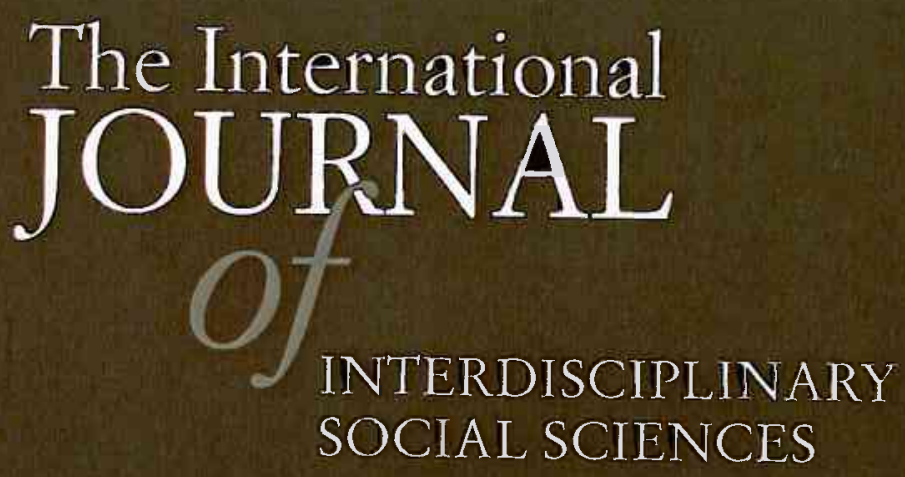

Volume 3, Number 8

Understanding the Burden on Palliative Care Home Carers: A Phenomenological Account

Andrew Guilfoyle, Lauren Breen, Colleen Fisher and Moira O'Connor 
THE INTERNATIONAL JOURNAL OF INTERDISCIPLINARY SOCIAL SCIENCES

http://www.SocialSciences-Journal.com

First published in 2008 in Melbourne, Australia by Common Ground Publishing Pty Ltd www.CommonGroundPublishing.com.

(c) 2008 (individual papers), the author(s)

C. 2008 (selection and editorial matter) Common Ground

Authors are responsible for the accuracy of citations, quotations, diagrams, tables and maps.

All rights reserved. Apart from fair use for the purposes of study, research, criticism or review as permitted under the Copyright Act (Australia), no part of this work may be reproduced without written permission from the publisher. For permissions and other inquiries, please contact <cg-support@commongroundpublishing.com>.

ISSN: 1833-1882

Publisher Site: http://www.SocialSciences-Journal.com

THE INTERNATIONAL JOURNALOOF INTERDISCIPLINARY SOCIAL SCIENCES is a peer refereed joumal. Full papers submitted for publication are refereed by Associate Editors through anonymous referee processes.

Typeset in Common Ground Markup Language using CGCreator multichannel typesetting system http://www.CommonGroundSoftware.com. 


\title{
Understanding the Burden on Palliative Care Home Carers: A Phenomenological Account
}

\author{
Andrew Guilfoyle, Edith Cowan University, WA, Australia \\ Lauren Breen, Edith Cowan University, WA, Australia \\ Colleen Fisher, University of Western Australia, WA, Australia \\ Moira O'Connor, Curtin University, WA, Australia
}

\begin{abstract}
Supporting carers is a key part of the Australian Federal Government's aged care policy. If novel ways of supporting carers can be found, then the financial and social benefits flowing from terminally ill people being able to be cared for at home will benefit not only the particular individuals involved, but health and social institutions Australia-wide. This occurs through the incorporation of the patient, primary caregiver, the family and their support networks into the plan of care. The research completed involved in depth interviews with in home palliative care providers $(n=18)$. In this paper we explore a theme around which carers spoke of negotiating the often disparate values and beliefs held by the patients and health professionals involved in their care, and defending and advocating for the needs of the patients. The data we present here illustrate a potential power differential inherent in the roles of 'professional' and 'carer' and highlight the potential for conflict when health professionals, unwittingly, impose their values, beliefs, and ideals onto the patients and/or carers. The carer's role as the nexus between the patients and the professionals might be an additional burden of care that, to date remains unacknowledged in palliative care research and practice. Suggestions for future research, and the translation of research into practice, are provided.
\end{abstract}

Keywords: Support Needs of Carers, Palliative Care

\section{Introduction}

$\mathrm{T}$ HIS PROJECT ADDRESSES an emerging and intrinsically interesting interdisciplinary issue for governments in terms of social, health and economic policy, that of supporting caregivers to enable terminally ill family members to remain in their homes. In Australia our population is ageing and will reach $16 \%$ or 3.6 million people over the age of 65 years by 2016. By the year 2041 this number will climb to 5.7 million or $25 \%$ of the population (Australian Institute of Health and Welfare and Commonwealth Department of Health and Family Services, 1997). With the aging of the population, the incidence of cancer and other chronic and life threatening illnesses will also rise, resulting in an increased demand on palliative care services. The desire of many with a terminal illness is that they are able to die in the comfort and familiar surroundings of their own home (Clark \& Seymour, 1999). This desire by its very nature requires the availability of someone to care for them. Given patient preference to remain at home, and the strain that this takes off health institutions, supporting caregivers is a key part of the Federal Government's aged care policy, albeit one that has received scant attention in the literature to date.

\section{The Role of the Family in Palliative Care}

Though once regarded as 'informal' (Clark, Reid, Morrison, Capewell, Murdoch, \& McMurray, 2008; Harding \& Higginson, 2001) extensions of health care programs, family caregivers are now responsible for a wide variety of services and activities that were formerly and formally provided by some traditional health service professions. The family as the unit of care is defined by the incorporation of the patient, primary caregiver, the family and their support networks into the plan of care (Sepulveda, Marlin, Toshida, \& Ulrich, 2002). It is widely recognized that the effective use of these informal networks can be a central source of emotional support and comfort throughout a person's illness (Health Department of Western Australia, 1997). Often family members provide informal care to the patient, which includes a range of supports such as managing medications, helping in personal care, emotional support and carrying out everyday household activities (Henwood, 1998). This informal care has been defined as "caring about, rather than merely caring for, or tending to, someone's needs" (Neale, 1993, p. 52). Family caregivers play a significant role in sustaining a patient's quality of life and certainly without this support many patients would find it impossible to remain

THE INTERNATIONAL JOURNAL OF INTERDISCIPLINARY SOCIAL SCIENCES, VOLUME 3, NUMBER 8, 2008

http://www.SocialSciences-Joumal.com, ISSN 1833-1882

- Common Ground, Andrew Guilfoyle, Lauren Breen, Colleen Fisher, Moira O'Connor, All Rights Reserved, Permissions: cg-support@commongroundpublishing.com 
at home at the end of their lives (Ramirez, Addington-Hall, \& Richards, 1998). Thus the family as the 'unit of care' underpins the philosophy and practice of palliative care. Through this model of service delivery, palliative care professionals across a range of disciplines attempt to provide holistic, quality endof-life care to terminally ill patients and their families (Palliative Care Australia (1998).

Every aspect of life is affected when an individual faces a terminal illness. Fear of death, symptoms, treatment, managing finances, anxiety about relationships and ability to cope can all contribute to making the world an unfamiliar and unsafe place (Kennett 2001). Coninected with this, family members in the community, who take on the primary responsibility of care of individuals, may experience a variety of physical, emotional, financial, and social pressures associated with the caring role (Connell, Janevic, \& Gallant, 2001; Fuller-Jonap \& Haley, 1995; KiecoltGlaser, Dura, Speicher, Trask, \& Glaser, 1991; Pruchno \& Potashnik, 1989). These dimensions of caregiver distress have been similarly observed across widely divergent cultures (Patterson et al., 1998).

Often families find caring for their loved one a rewarding and satisfying experience (Berg-Weger, Rubio, \& Tebb, 2001) and it is not that all care-givers perceive their role negatively ( $\mathrm{Li}$, Seltzer, \& Greenberg, 1999). It is clear though, that alongside the rewards there are many challenges facing caregivers, including being responsive to needs of the patient, the unpredictable nature of caring, and its performance around the clock (Neale, 1993). Invariably, this creates what some have labelled a potential 'burden' on family members.

\section{The Burden on Caregivers}

Despite an emerging literature on the positive aspects of caring (see for example Cohen, Colantonio, \& Vernich, 2002), overall the evidence linking caring to negative health outcomes is compelling and consistent (see reviews by Brazil, Bedard, \& Willison, 2002; Durmont, Turgeon, Allard, Gagnon, Charbonneau, \& Vezina, 2006). In addition to individual ramifications for caregivers, this issue has important policy implications because negative health outcomes can compromise both caregivers' health and their ability to provide continued care (Colantonio, Kositsky, Cohen, \& Vernich, 2001). Research demonstrates that caregivers are impacted psychologically, socially, and emotionally. Caring has been associated with increased levels of depressive symptoms and a higher prevalence of clinical depression and anxiety. The authors of one study suggested that $46 \%$ to $83 \%$ of caregivers experience significant symptoms of depression (Gallagher, Rose, Rivera, Lovett, \& Thompson, 1989) with another team estimating the prevalence to be between $28 \%$ and $55 \%$ (Schúlz, O'Brien, Kookwala, \& Fleissner, 1995). Anxiety has been found to be present in $17.5 \%$ of caregivers compared to $10.9 \%$ of subjects in a matched control group (Cochrane, Goering, \& Rogers, 1997; Gwether \& Strulowitz, 1998). An increased incidence of anxiety correlates with findings from research that has revealed a higher amount of psychotropic drug use and increased incidence of alcohol use among caregivers than non-caregivers (Grafstrom, Fratiglioni, Sandman, \& Winblad, 1992; Saad, Hartman, Ballard, Kurian, Graham, \& Wilcock, 1995).

There is certainly a wealth of research documenting the impact that the caring role has on caregivers' everyday lives (see for example Cain \& Wicks, 2000; Grande, Todd, \& Barclay, 1997; Henwood, 1998; Hudson, 2004). In a UK survey of caregivers, conducted by the Carers' National Association (Henwood, 1998) it was found that $70 \%$ of caregivers were supporting patients for at least seven hours per day. Inevitably this leads to stress, isolation and emotional strain (Gaugler et al., 2005) and the closer the relationship between the caregiver and the patient, the greater this burden is likely to be. This can also result in a major disruption to caregivers' family functioning, particularly as the disease progresses (Sherman \& Simonton, 1999), and if the caregiver is also a parent of young children this may impact on care of children and result in the juggling of multiple roles (Wilson, 2004).

A further implication for caregivers of patients receiving palliative care is the emotional burden of facing the impending death of a loved one (Dracup, Evangelista, Doering, Tullman, Moser \& Hamilton, 2004; Neale, 1993). This may result in anxiety and depression and feelings of being restricted and isolated (Payne, Smith, \& Dean, 1999). Broback and Bertero's (2003) findings from a phenomenological study of caregivers in Sweden indicate that caregivers experienced feelings of 'insufficiency' resulting from a need to adjust, deal with feelings of uncertainly and accommodate a change in identity. Further, the association between care giving and psychological distress is compounded by family dynamics such as individual tolerance for certain types of behaviours, different levels of interaction and the unique relationships of family members (Loke, Liu, \& Szeto, 2003, for cultural differences; Dracup, et al, 2004 for spouses; Fromme \& Drach 2005 for analysis of men as caregivers; Milne, Hatzidimitriadou, Chryssanthropoulou \& Owen, 2001 for older caregivers). Often the key determinant of burden is availability of emotional and instrumental social support $(\mathrm{Li}$, Seltzer, \& Greenberg, 1999) and motivations for providing in home care (Cain \& Wicks, 2000; Stajduhar \& Davies, 2005). Coping style also plays a role in mitigating the impact of stress, caregivers 
who are accepting of the loved one's death and use a more problem solving than emotional coping style experience less caregiver strain and burden (Redinbaugh, Baum, Tarbell, \& Arnold, 2003). In general females, younger people and spouses appear most vulnerable to distress (Payne et al., 1999).

Surprisingly, despite the emphasis in the literature on caregiver burden, there is little in the way of intricately elucidating the support needs of palliative care family caregivers per se (Wilkes, White, Mohan, \& Beale, 2006; Wilson, 2004). Reviews have asked generally 'what is the best way to help caregivers' (Harding \& Higginson, 2003) or how to support 'quality' of life' (Lorenz et al., 2008) and suggested that informal care giving is complex (Clark et al., 2008). This research tends to focus on interventions which highlight the role of professionals, including the need for health professionals to communicate with families, support home care and demonstrate empathy and compassion (Ashby \& Dowding, 2004; Rabow, Hauser, \& Adams, 2004; Ryan, 2005) and to promote feelings of control and self efficacy for caregivers (Broback \& Bertero, 2003). A recent systematic review of studies across disciplines examining patient and/or caregiver preferences regarding end of life communication highlighted the importance of the health professional's empathy, honesty, sensitivity and communication style (Parker et al., 2007) with general recommendations for health professionals' training. Often the amorphous nature of these concepts make them very difficult to put into practice without clear guidelines and protocols and the authors also give few indications about how such interventions may work in practice. Furthermore, a review of the literature revealed significant discrepancies in patients' understandings of information received from interdisciplinary health professionals, and their health professionals' perceptions of the patients' understandings of the information provided (Hancock et al., 2007). Ingleton, Payne, Nolan, and Carey (2003) concluded that there is to date insufficient evidence to draw any conclusions about the efficacy of respite services for caregivers. While more recently Zimmerman, Reichelmann, Kryzyzanowska, Rodin, \& Tannockl (2008), after a meta-analytic review suggested there was consistent evidence for better caregiver satisfaction from receiving specialised palliative care, but noting that satisfaction is a construct which is hard to measure in this context.

The fact that research seems to focus on the efficacy of professional care rather than caregivers experiences per se might be a condition of what Fisher, Guilfoyle, and O'Connor (2006) suggest is the "distance between palliative care philosophy that clearly locates the patient and his/her family as central to, and prime drivers of, patients' care needs, and how this manifests in practice" (p. 16). This paper is dedicated to prioritising the experiences of caregivers and in particular it moves beyond quantitative measurements of caregiver satisfaction and towards a more careful understanding of burden.

\begin{abstract}
Aim
Drawing on data drawn from a larger study of the support needs of palliative care home caregivers, the aim of the present paper is to focus on understanding specific burdens of care. By examining the speech of caregivers as they account for their experiences interacting with health professionals we are better positioned to understand their needs and identify any phenomena of burden in caring bound within these interactions. This should help health professionals in improving interventions for the support needs of palliative care home caregivers.
\end{abstract}

\section{Methods}

\section{Research Design}

This study employed an in-depth phenomenological qualitative design (Moustakas, 1994). It utilized semi-structured interviews with caregivers of patients receiving palliative care. Interviews with the caregivers were the primary focus of the research and enabled us to elicit issues salient to them in terms of support needs in the context of caring for a person with a terminal illness and impending death. The interviews focused on the caregivers' stories and these stories represent the substance of their lived identities within providing care. Additionally, the interviews advance the literature beyond the single voice of standardized, quantitative instruments used in much research on caregiver: support needs by an exploration of a person's 'life world' (Polkinghorne, 2005)

\section{Participants}

18 caregivers (all female except one) from rural ( $\mathrm{n}$ $=6$ ) and metropolitan $(\mathrm{n}=12)$ Western Australia were involved in the study. Caregivers were either currently caring for a person receiving palliative care or had cared for a person who received palliative care in the last 2 years, (as partner 14; mother 2 , daughter, 2) but were at least 3 months post bereavement. This time-frame post-death is appropriate given the vulnerability of the family immediately after bereavement but, at the same time, permits the caregiver to reflect on the caring experience and the support needs that would facilitate this role. 


\begin{abstract}
Materials
Participants were asked to give an account of how they are living with/have lived with the experience of caring, focusing on topics such as their caring role, difficulties, successes, support needs and major adjustments.
\end{abstract}

\section{Procedure}

Recruitment was continuous for a period of 6 months. We were able to recruit participants to this study through a home hospice service, which supports 'inhome' palliative care services and bereavement support across Westem Australia through a statewide caregiver network; and through feature articles and advertisements in community newspapers throughout the state. If a caregiver was willing to participate s/he was asked to contact the qualified research assistant. By telephone, the researcher further explained the study details, confirmed the inclusion criteria had been met, organised a time for interview and indicated the need for written consent.

Prior to the commencement of the research, appropriate consent forms and ethics clearances were obtained, full details of the study were given to participants, any questions they may have answered, and participants informed that they were under no obligation to answer any question with which they do not feel comfortable and could withdraw from the research, without prejudice, at any time. As the issues covered in the interviews were of a personal nature involving grief, information was provided to participants of places they may attend or phone numbers they may call, should they wish counselling or other assistance.

\section{Thematic Data Analysis}

All interviews were audio recorded and transcribed verbatim. All names have been replaced with pseudonyms. The transcriptions were checked against the respective audio tapes to ensure an accurate representation of speech. Following this, the data were entered into NVivo8 software (QSR International, 2007). Data were coded in the first phase by the first named researcher reviewing the transcripts in NVivo 8 and identifying any initial salient features of the discourse that were of interest to the research aims. In the next phase this researcher coded these into clusters of significant statements which represented the essence of caregiver experiences (i.e., le Vasseur, 2003) when interacting with professionals in the context of 'talking of death/dying'. In this phase a set of 19 significant statements was identified and were generally grouped into 7 broad clusters of meaning using NVivo8 software such "negotiating disparate beliefs and values"; "defending or advocat- ing the needs of patients". For each cluster a short interpretative definition was developed. This initial coding was then subject to a process of researcher triangulation and cross-case analysis (Creswell, 2007) in the third phase. Through a series of team meetings the significant statements coded into each of the 7 clusters were reviewed collectively by all members of the team. In this validation phase each team member provided their own interpretation of the statements in each cluster and by open dialogue we compared the statements against each other, and at times referred back to the original transcripts. After reviewing the statements, based on a consensus group decision, clusters were adjusted, collapsed and their definitions modified such that a set of 16 statements remained and were represented in 5 clusters. The final agreed set of clusters and selected representative significant statements followed by interpretative discussion is presented below. As the 'difference in world view' cluster was salient we dedicate more space to the interpretation of statements within this.

\section{Findings}

\section{Sharing the Trajectory of their IIIness}

Many of the caregivers highlighted the advantages of provided in-home care to their ill family members. The key advantage was being able to help their family member by being in position to negotiate and share the trajectory of their illness within the home environment, the spousal relationships and within the wider family unit. For example, one woman who provided palliative home care for her husband affirmed;

"I was really glad that he came home, not just for myself but the family. We had the chance to talk to him and talk about things that he probably wouldn't have spoken about had he been in hospital. Talking about what we could do, where we were going to go, finalising things... as you know a wife of the person that's dying there are things that you need to say to each other to help you on your way, both of you on your way."

\section{Positioning of Talk about Death and Dying}

Conversations between caregiver and patient concerning dying, death, and the future, were considered by the caregivers to be best positioned within these spousal and familial relationships in the first instance. These conversations might or might not require the involvement of health professionals and often the preference is for them to occur inside of the immediate personalised care. One man who provided palliative home care for his wife described; 
"Heather (patient) sat bolt upright in bed and said I'm going to die a horrible death and so that took some comforting and again we cried together but then we just got on with life, we just said there's a lot of living to do because you don't know how long you've got and so we just got on with life."

\section{Conditional Needs for Professional Help}

The desire to discuss death/dying within the personal space of caregiver and patient did not preclude the need for professional help. For many caregivers, the involvement of health professionals is critical for the care and well being of their family member. The caregivers acknowledged the key roles played by health professionals in the care of the patients. In particular, some spoke about the importance of visiting the patient at home and talking with rather than about them. As one caregiver of her husband illustrated

\begin{abstract}
"It would be nice if they (religious based, inaudible) visit too, if that's possible, they came to the home because they are absolutely wonderful, they just, they're very spiritual and even though we're not religious they're just (inaudible), very kind. I think it would have helped John to just see someone to talk to him. I felt that he was left on his own a lot. I'm sure there would have been things he wanted to talk about."
\end{abstract}

\section{Patient's Worldview}

In this light some caregivers reported that their loved ones were more than willing to talk openly about the dying trajectory, their stage of illness, and concepts of death and dying with professionals. Importantly, however, the willingness to do so depended greatly on the personality and worldview of the patient. For example below the patient was depicted as scientific and matter-of-fact and as being amenable to the direct and frank discussion of these issues. For instance;

"He was interested. What he wanted was a chart, being a scientist, showing, like for instance in the hospital bed (inaudible) measurements and he wanted to plot that and when they intercepted with the horizontal line it said 'death'. He wanted to see where he was going, how close he was getting to that."

Some caregivers described the involvement of professionals as working ideally when the informational and attitudinal needs of the patients aligned with that of the professionals. One woman caring for her father recalled the professionals were "very smiling and welcoming when we arrived. They were able to make jokes about Dad's illness and Dad's death and that was very important (inaudible) because he just wanted it to be real and out in the open."

\section{Difference in Worldview}

However, some caregivers thought that some professionals were not always open to the frank discussion of death and dying with the patients, even when the patients themselves wanted candid conversations. The incongruence between these patients' needs and professional discomfort often meant that these topics were not discussed in the manner matching the patients' needs. Again an example of a 'scientific' approach by a patient was noted.

\begin{abstract}
"He was a biology graduate, very matter of fact, and there's no point in suffering and so he, we had to have this conversation when it was, that was very difficult in the hospital because I guess not many people have that kind of very 'if I'm going to die I'll do it as quick as I can' attitude and not to hold on where there's life there's hoping, carry on however vegetative you are and he did definitely not want that."
\end{abstract}

For us the critical contrast occurred in the talk of caregivers who defined their patient as less willing and open to conversations about the state of their illnesses and their approaching deaths. Here the caregivers reported a burden in their need to be guarded about the professionals broaching these topics in front of the patients. These caregivers reported being very concerned about the impact of professional intervention through this topic, on their loved ones. To illustrate, one woman caring for her father described, "they'd talk over him and talk about when he was going to die and everything and he was listening the whole time and then they'd left the room he'd say "oh they haven't got me down for long time". Other caregivers spoke of advocating or actively 'fighting' for the perspective of their ill family member to be recognized for the professionals involved in their care. One woman caring for her mother emphasized this additional burden of care by stating;

"She did everything (complied with medical regime), she was quite happy, she just didn't want it (the cancer) mentioned, she didn't want to be told that she had it and a lot of people don't. ... I had to stand up a bit for my Mum with one of the nurses. I said, 'don't mention cancer because she doesn't want to know'. She said 'she has a right, and I will tell her' and I said 'no, you either agree to come into the house and not mention cancer (inaudible) or you don't 
come in at all'. She decided to come out and sort it out but this is Mum's life, she doesn't want to know. I mean she knew; if she doesn't want to be told face to face then I think that's her right."

For other caregivers, it was not whether or not death and dying are introduced in conversations between the professional and patient, but how the topics of death and dying are raised and defined by the professionals within these conversations. In particular, the use of platitudes and euphemisms by the professionals, especially if they were value-laden or culturally based impositions, was a significant concern to the caregivers. For example, one woman who cared for her husband stated, "I found some of the things staff said condescending. They talk about a journey and it's not a journey, it's a nightmare," while another woman who cared for her father described;

"The only thing that comes to mind really is when people would talk about God because God has no place in my life or my father's life and when people would say things to me like 'It's in God's hands' or 'after he dies he'll be in a better place'. That made me really angry because it's not where I'm at."

These caregivers expressed considerable concern about the incongruence between the values and beliefs held and asserted explicitly by the professionals and the values and beliefs of the patients. For instance, one woman caring for her mother explained the misalignment and its impact by stating;

"a lot of the palliative care people are pastors and you know, very nice and very well meaning but they weren't much good to us and... all the stuff about being in a better place was just rubbish and (inaudible) you know you don't want that, we know what we want but you've got to convince other people of your beliefs or nonbeliefs without upsetting them and you just want to get on and make it comfortable and easy and I don't know how you do that."

Furthermore, some caregivers explained their role in defending against the misalignment and guarding its full impact on themselves and the patient. We cannot know from the present data the pervasiveness of this positional shielding but argue at a minimum, it clearly added in the immediate sense, to the caregivers' burden of care.

"One of the doctor's said to Trevor, 'are you religious?' and he said 'no, I'm not' so she said 'so you don't believe in life after death?' And he said 'no, I don't' and she said 'well you're going to find dying very difficult then' (said out loud). I mean it just blew me away. Then you're very shocked and then sit up. She said 'what do you want?' And I was in on the conversation with the words because I was so shocked and she said 'well what do you want Trevor?' Oh he said 'I want my life back the way it was', and she said 'well that's not possible because you're going to die' and it was so brutal, the way the conversation went, it was so brutal. I couldn't believe that doctor, she said that she was religious herself, I think she should have left that at the door. I don't think she should have taken that in and I think it was unnecessary to bring that into the conversation because everybody's got their own beliefs and I found that quite shocking."

In the context of home based palliative care, the relationship between the caregiver and the patient is critical. The caregivers spoke of negotiating the often disparate values and beliefs held by the patients and professionals involved in their care, and defending and advocating for the needs of the patients. The data we present here illustrate the potential power differential inherent in the roles of 'professional' and 'caregiver' in conflict over professionals, wittingly or unwittingly, imposing their values, beliefs, and ideals onto the patients and/or caregivers. Thus relegating the caregiver's role in defining what can be discussed.

\section{Discussion}

Many caregivers positioned themselves as providing the nexus between the patients and the professionals providing the palliative care. We argue it should be realised by professionals that when the mediatory role played by the caregivers is exacerbated, this can act as a potential additional burden of care. While for some patient-caregiver contexts professionals intervention clearly lighten a burden of care, in other contexts we need to be reflective about how interventions interact with this burden.

The additional burden of care for caregivers in providing the nexus between the patients and the professionals to date remains unacknowledged in palliative care research and practice. In a broad sense our findings lend some support to research in recent years, which has challenged some taken-for-granted assumptions of palliative care. For example, the notion that interdisciplinary teams provide higher quality palliative care services delivery suggests a critical move away from a hierarchical model. But the evidence to date shows this move has not removed the medical dominance in care and that the patient and their caregivers are not necessarily shifted to a position as the central unit of care ( $\mathrm{O}^{\prime} \mathrm{Connor}$, 
Fisher, \& Guilfoyle, 2006). Furthermore, the power inherent within palliative care provision needs to be addressed. Patients and their families are often silenced by, and their needs positioned as secondary to, the needs of the professionals involved in their care who aim towards achieving a 'good death' for the patient (Guilfoyle, Fisher, \& O'Connor, 2003; Fisher et al., 2006). There is recognition of a powerful ideology too, within palliative care philosophy and practice around 'the right way to die' and the need to 'openly discuss death' (Guilfoyle et al., 2003). If the definitions of what is death or dying are provided by professionals; dying patients and their families can be implicitly labelled as either 'good' or 'bad' depending on how well they fit or conform with professional definitions of a 'good death' (Guilfoyle et al., 2003; Hart, Sainsbury, \& Short, 1998). Further any resistance to the professional's point of view is characterised by the professionals as a form of denial, maladaptive behaviour, a disturbance in their necessary anticipatory grief or failure to engage in the 'proper' preparation for death (Fulton, Madden, \& Minichiello, 1996). Clearly as the practice of palliative care 'matures' then there is a need to unpack the philosophies and power contexts underpinning care and whether they do fully 'centralise' the role of family caregiver.

This paper is limited to an exploration of support needs through 12 one-off individual interviews up to 2 years of post bereavement. We supplied a thematic analysis to capture the essence of some of these experiences for caregivers when interacting with professionals around the notions of death/dying or trajectory of illness. Other themes were present in this data and we hope to explore these more fully within the present data and with different samples. These include themes of the role of support agencies in supporting the caregiver and related relationships/expectations between caregiver and these supports, in respect of the symbiotic relationship of caregiver and patient; barriers to accessing support; follow up bereavement / aftercare. In particular for the latter we found cases where professionals work hard to prepare caregivers to anticipate grief but do not follow through on providing bereavement support.

We will explore differences between caregivers' experiences in regional and urban settings more closely and the effects of relationship of caregiver and patient beyond spousal relationships. Also our focus on experiences might be better served by contrasting length of bereavement, through longitudinal analysis and benefit from interviews prior to bereavement also (mindful of essential research ethics for sampling vulnerable caregivers and patients). We advocate for other qualitative methodologies including case study of poor or good experiences and nar- rative approaches for a more discursive analysis of the data which could show more intricately how emotion-laden interactions between caregiver and professionals, and any power struggles within this, affects identity and processes of care. Our data did not identify professionals per se and in future we will be more cognizant of the interactions between caregivers and types of disciplines of professionals involved. In future we aim for a more interdisciplinary review and analysis considering the reports of burden of care discussed in case management literature. We argue for, and include ourselves in, the need for a greater interdisciplinary dialogue of diverse perspectives and shared investment in the complex future of palliative care.

\section{Addressing the Burden on Palliative Care Caregivers?}

We therefore argue for a fine grained examination of caregivers' speech when describing their lived experiences of caring and the needs of the patient under their care. Through research palliative care professionals can understand that, much like in the grief and bereavement literature (Breen \& O'Connor, 2007), a one size approach does not fit all and they also need to recognize that the needs of patients and their families are multifaceted, unique, and culturallydetermined (Tong \& Spicer, 1994). Patients and their families have unique needs and information provided by professionals needs to be tailored to meet them. In a general sense the carers in our study appear to want their role in representing the patient to be acknowledged by the professionals as this can help them to better meet the needs of their loved ones receiving care.

What is clear is that many caregivers had a highly symbiotic relationship between each caregiver and patient and defined caring for their family member as an opportunity to be close with them and this potentially flows into a need to guard their patient as best they could from any negative external influences.

The difficulty then for professionals is negotiating the knowledge provided by family caregivers with the need to be 'honest' despite the opinions of the caregiver. There might indeed be situations where the professional should decide to intervene and override the caregiver (Fisher, 2003). The assumption that families are functional, cohesive and supportive following family crises including terminal illness (Fisher, 2003) and bereavement (Breen \& O'Connor, in press) have been challenged. Still, we have to question whether or not professionals can insist on what is the truth or right of the patient beyond that defined by the caregiver. We need to challenge professionals to move from intention to be client centred in actuality. Can and should we presume caregivers' 
needs reflect patients' needs? Should professionals override the opinion of caregivers in their interventions and if so, under what circumstances would such actions be appropriate? How can the relationship between caregiver, patient, and professional be best negotiated? Will professionals really want to acknowledge the family as unit of care and hand responsibility to the caregiver and/or relinquish their role thus as the 'expert' in providing care? Would doing so add to or diminish the overall burden of care? The onus is on professionals to acknowledge and answer these questions even when the answers challenge much that is integral to being 'expert' or 'professional'? Those who can institute reflexive practice within these questions can best claim both expertise and professionalism.

\section{References}

Ashby, M. E., \& Dowding, C. (2004). Hospice care and patients' pain: Pain communication between patients, relatives, nurses and doctors. International Journal of Palliative Nursing, 7(2), 58-67.

Australian Institute of Health and Welfare \& Commonwealth Department of Health and Family Services. (1997). Older Australia at a glance. Canberra: Australian Government.

Berg-Weger, M., Rubio, D. M., Tebb, S. S. (2001). Strengths-based family practice with family caregivers of the chronically ill: Qualitative insights. Families in Society, 82, 263-272.

Brazil, K., Bedard, M., \& Willison, K. (2002). Correlates of health status for family caregivers in bereavement. Journal of Palliative Medicine, 5(6), 849-855.

Breen, L. J., \& O'Connor, M. (2007). The fundamental paradox in the grief literature: A critical reflection. Omega: The Journal of Death and Dying, 55, 199-218.

Breen, L. J., \& O'Connor, M. (in press). Family and social networks after bereavement: Experiences of support, change, and isolation. Journal of Family Therapy.

Broback, G., \& Bertero, C. (2003). How next of kin experience palliative care of relatives at home. European Journal of Cancer Care 12, 39-346.

Cain, C. J., \& Wicks, M. N. (2000). Caregiver attributes as correlates of burden in family caregivers coping with chronic obstructive pulmonary disease. Journal of Family Nursing, 6(1), 46-68.

Clark, A. M., Reid, M. E., Morrison, C. E., Capewell, S., Murdoch, D. L., McMurray, J. J. (2008). The complex nature of informal care in home-based heart failure management. Journal of Advanced Nursing, 61(4), 373-383.

Clark, D., \& Seymour, J. (1999). Reflections on palliative care. Buckingham, UK: Open University Press.

Cochrane, J. J., Goering, P. N., Rogers, J. M. (1997). The mental health of informal caregivers in Ontario: An epidemiological survey. American Journal of Public Health, 87, 2002-2007.

Cohen, C. A., Colantonio, A., \& Vernich, L. (2002). Positive aspects of caregiving: Rounding out the caregiver experience. International Journal of Geriatric Psychiatry, 17, 184-188.

Colantonio, A., Kositsky, A., Cohen, C., \& Vernich, L. (2001). What supports do caregivers of elderly want? Results from the Canadian Study of Health and Aging. Canadian Journal of Public Health, 92, 376-379.

Connell, C. M., Janevic, M. R., \& Gallant, M. P. (2001). The costs of caring: Impact of dementia on family caregivers. Journal of Geriatric Psychiatry and Neurology, 14, 179.

Creswell, J. (2007). Qualitative inquiry \& research design: choosing among five approaches ( $2^{\text {nd }}$ ed.). Thousand Oaks: Sage.

Dracup, K., Evangelista, L. S., Doering, L., Tullman, D., Moser, D. K., \& Hamilton, M. (2004). Emotional well-being in spouses of patients with advanced heart failure. Heart and Lung, 33(6), 354-361.

Durmont, S., Turgeon, J., Allard, P., Gagnon, P., Charbonneau, C., \& Vezina, L. (2006). Caring for a loved one with advanced cancer: determinants of psychological and distress in family caregivers, 9(4), 912-921.

Fisher, C. (2003). The invisible dimension: Abuse in palliative care families. Journal of Palliative Medicine, 6, 257-254.

Fisher, C., Guilfoyle, A., \& O'Connor, M. (2006). 'Listening with the third ear and other expertises': A case analysis of social work discourse in the context of the multidisciplinary palliative care team. Australian Community Psycho-
logist, 18(2), 7-19.

Fromme, E. K., Drach, L. L. (2005). Men as caregivers at the end of life. Journal of Palliative Medicine, 8(6), 849-855.

Fuller-Jonap, F., \& Haley, W. E. (1995). Mental and physical health of male caregivers of a spouse with Alzheimer's disease. Journal of Aging and Health, 7, 99-118.

Fulton, G., Madden, C., \& Minichiello, V. (1996). The social construction of anticipatory grief. Social Science and Medicine, 43, 1349-1358.

Gallagher, D., Rose, J., Rivera, P., Lovett, S., Thompson, L. W. (1989). Prevalence of depression in family caregivers Gerontologist, 29, 449-456.

Gaugler, J.E., Hanna, N., Linder, J., Given, C.W., Tolbert, V., Kataria, R., \& Regine, W.F. (2005). Cancer caregiving and subjective stress: A multi-site, multi-dimensional analysis. Psycho-oncology, 14, 771-785.

Grafstrom, M., Fratiglioni, L., Sandman, P. O., \& Winblad, B. (1992). Health and social consequences for relatives of demented and non-demented elderly: A population-based study. Journal of Clinical Epidemiology, 45, 861-870.

Grande, G. E., Todd, C. J., \& Barclay, S. I. G. (1997). Support needs in the last year of life: Patient and care dilemmas. Palliative Medicine, 11, 202-208.

Guilfoyle, A., Fisher, C., \& O'Connor. (2003). Talking care. The construction of patients' social identity within the context of collaborative palliative care teams. Proceedings of Talking Health the $3^{\mathrm{RD}}$ Murdoch Symposium on Talk-inInteraction. Rockingham, Western Australia. 
Gwether, L. P., \& Strulowitz, S. Y. (1998). Care-giver stress. Current Opinion in Psychiatry, 11, 431434.

Hancock, K., Clayton, J. M., Parker, S. M. Walder, S., Butow, P., N., Carrick, S., Currow D., Ghersi, D., Glare, P., Hagerty, R., \& Tattersall, M. H. N. (2007). Discrepant perceptions about end-of-life communication: A systematic review. Journal of Pain and Symptom Management, 34, 190-200

Harding, R., \& Higginson, I. (2001). Working with ambivalence: Informal caregivers of patients at the end of life. Support Care Cancer, 9, 642-645.

Harding, R, \& Higginson, I. J. (2003). What is the best way to help caregivers in cancer an palliative care? A systematic literature review of interventions and their effectiveness. Palliative Medicine, 17, 63-74.

Hart, B., Sainsbury, P., \& Short, S. (1998). Whose dying? A sociological critique of the good death. Mortality, 3, 65-77.

Health Department of Western Australia (1997) Palliative care. Perth, Australia: Author.

Henwood, M. (1998). Ignored and invisible? Carers experience of the NHS. London: Carers' National Association.

Hudson, P. (2004). Positive aspects and challenges associated with caring for a dying relative at home. International Joumal of Palliative Nursing, 10(2), 58-65.

Ingleton, C., Payne, S., Nolan, M., \& Carey, I. (2003). Respite in palliative care: A review and discussion of the literature. Palliative Medicine, 17, 567-575.

Kiecolt-Glaser, J. K., Dura, J. R., Speicher, C. E., Trask, O. J., \& Glaser, R. (1991). Spousal caregivers of dementia victims: Longitudinal changes in immunity and health. Psychosomatic Medicine, 53, 345-362.

Kennett, C. (2001). Psychosocial day care. In J. Hearn \& K. Myers (Eds.), Palliative day care in practice (pp. 59-78). Oxford: Oxford University Press.

le Vasseur, J. J. (2003). The problem of bracketing in phenomenology. Qualitative Health Research, 13, 408-420.

Li, L. W., Seltzer, M. M., \& Greenberg, J. S. (1999). Change in depressive symptoms among daughter caregivers: An 18month longitudinal study. Psychology and Aging, 14, 206-219.

Loke, A. Y., Liu, C. F., \& Szeto, Y. (2003). The difficulties faced by informal caregivers of patients with terminal cancer in Hong Kong and the available social support. Cancer Nursing, 26, 276-283.

Lorenz, A., Lynn, J., Dy, S., Shugarman, L., Wilkinson, A., Mularski, R., Morton, S., Hughes, R., Hilton, L., Maglione M., Rhodes, L., Rolon, C., Sun, V., \& and Shekelle, P. (2008). Annals of Internal Medicine, 14892), 147-159

Milne, A., Hatzidimitriadou, E., Chryssanthropoulou, C., Owen, T. (2001). Caring in later life: Reviewing the role of older carers. London: Help the Aged.

Moustakas, C. (1994). Phenomenological research methods. Thousand Oaks, CA: Sage.

Neale, B. (1993). Informal care and community care. In D. Clarke (Ed.), The future for palliative care: Issues of policy and practice (pp. 53-67). Buckingham, UK: Open University Press.

O'Connor, M., Fisher, C., \& Guilfoyle, A. (2006). Interdisciplinary teams in palliative care: A critical reflection. International Journal of Palliative Nursing, 12, 132-137.

Palliative Care Australia (1998). "The hardest thing we have ever done" - The social impact of caring for State of the Nation - Report on National Census of Palliative Care Services Retrieved from www. palliativecare .org.au (August
2008)

Parker, S. M., Clayton, J. M., Hancock, K., Walder, S., Butow P. N., Carrick, S., Currow, D., Ghersi, D., Glare, P., Hagerty, R., \& Tattersall, M. H. N. (2007). A systematic review of prognostic/end-of-life communication with adults in the advanced states of a life-limiting illness: Patient/caregiver preferences for the content, style, and timing of information. Journal of Pain and Symptom Management, 34, 81-93.

Patterson, T. L., Semple, S. J., Shaw, W. S., Ye, I., He, Y., Zhang, M. Y., Wu, W., \& Grant, I. (1998). The cultural context of caregiving: A comparison of Alzheimer's caregivers in Shanghai, China and San Diego, California. Psychological Medicine, 28, 1071-1084.

Payne, S., Smith, P., \& Dean, S. (1999). Identifying the concerns of informal carers in palliative care. Palliative Medicine $13,37-44$. Polkinghome, D. E. (2005). Language and meaning: Data collection in qualitative research. Journal of Counseling Psychology,
52, 137-145.

Pruchno, R. A., \& Potashnik, S. L. (1989) Caregiving spouses: Physical and mental health in perspective. Journal of the American Geriatrics Society, 37, 697-705.

QSR International (2007). NVivio8. Melbourne, Australia. QSR International Pty Ltd.

Rabow, M. W., Hauser, J. M., \& Adams, J. (2004). Supporting family caregivers at the end of life: "They don't know what they don't know". JAMA: Journal of the American Medical Association, 291, 483-495. Ramirez, A., Addington-Hall, J., \& Richards, M. (1998). ABC of palliative care: The carers. British Medical Journal, 316,
208-211.

Redinbaugh, E. M., Baum, A., Tarbell, S., \& Amold, R. (2003). End-of-life caregiving: What helps family caregivers cope? Journal of Palliative Medicine 6, 901-909.

Ryan, P. Y. (2005). Approaching death: A phenomenologic study of five older adults with advanced cancer. Oncology Nursing Forum, 32, 1101-1108.

Saad, K., Hartman, J., Ballard, C., Kurian, M., Graham, C., Wilcock, G. (1995). Coping by the carers of dementia sufferers. Age and Ageing, 24, 495-498.

Schulz, R., O'Brien, A. T., Kookwala, J., \& Fleissner, K. (1995). Psychiatric and physical morbidity effects of dementia caregiving: Prevalence, correlates, and causes. Gerontologist, 35, 771-791.

Sepulveda, C., Marlin, A., Yoshida, T., \& Ulrich, A. (2002). Palliative care: The World Health Organization's global perspective. Joumal of Pain and Symptom Management, 24, 91-96. 
Sherman, A. C., \& Simonton, S. (1999). Family therapy for cancer patients: Clinical issues and interventions. Family Journal, 7, 39-50.

Stajduhar, K.I., \& Davies, B. (2005). Variations in and factors influencing family members' decisions for palliative home care. Palliative Medicine, 19(1), 21-32.

Tong, K. L., \& Spicer, B. J. (1994). The Chinese palliative patient and family in North America: A cultural perspective. Journal of Palliative Care, 10, 26-28.

Wilson, V. (2004). Supporting family carers in the community setting. Nursing Standard, 18 (29), 47-55.

Wilkes, L. M., White, K., Mohan, S., \& Beale, B. (2006). Accessing metropolitan cancer care services: Practical needs of rural families. Journal of Psychosocial Oncology, 24, 85-101.

Zimmerman, C., Reichelmann, R., Kryzyzanowska, M., Rodin, G., \& Tannockl, I. (2008). Effectiveness of specialized palliative care: A systematic review. Journal of the American Medical Association, 299(14), 1698-1709.

\section{About the Authors}

Dr. Andrew Guilfoyle

Dr. Andrew Guilfoyle, Ph.D., is a Lecturer in the School of School of Psychology and Social Science teaching qualitative research. Andrew's research has focused on improving the provision of health services, community health and well being, particularly for children and families including Indigenous and other cultural groups.

\section{Dr. Lauren Breen}

Her Ph.D., is a Postdoctoral Research Scholar in the Centre for Social Research, School of Psychology and Social Science, Edith Cowan University. Dr Breen's research interests centre on applied research in four domainsdeath and dying, grief and loss, children and families, and health, disability, and wellness. She is particularly interested in naturalistic research designs and qualitative methodologies.

\section{Dr. Colleen Fisher}

Dr. Colleen Fisher is a senior lecturer in the School of Population Health at the University of Western Australia. She has been involved in research into psychosocial aspects of palliative care, health promotion, women's heatlh, and prevention, early intervention and responses to family and domestic violence.

\section{Dr. Moira O'Connor}

Dr. Moira O'Connor is a Senior Research Fellow in the WA Centre for Cancer and Palliative Care. Her main areas of research include: psycho-oncology and psychosocial aspects of palliative care; women's health; and health psychology. Her current projects include the role of the community pharmacists in palliative care; breast cancer follow up: what works best; how health professionals communicate about sexuality and intimacy issues; and carers' needs in palliative care. 


\section{The International \\ JOURNAL OfinTHRIDSCIPINARY SOCIAL SCUNCES}

\section{EDITORS}

Mary Kalantzis, University of Illinois, Urbana-Champaign, USA.

Bill Cope, University of Illinois, Urbana-Champaign, USA.

EDITORIAL ADVISORY BOARD

Patrick Baert, Cambridge University, Cambridge, UK.

Norma Burgess, Syracuse University, Syracuse NY, USA.

Vangelis Intzidis, University of the Aegean, Rhodes.

Paul James, RMIT University, Melbourne, Australia.

José Luis Ortega Martín, Universidad de Granada, Spain.

Francisco Fernandez Palomares, Universidad de Granada, Spain.

Miguel A. Pereyra, Universidad de Granada, Spain.

Constantine D. Skordoulis, University of Athens, Athens, Greece.

Chryssi Vitsilakis-Soroniatis, University of the Aegean, Rhodes, Greece.

Please visit the Journal website at http://www.SocialSciences-Journal.com for further information about the Journal or to subscribe. 


\section{THE UNIVERSITY PRESS JOURNALS}

International Journal of the Arts in Society

Creates a space for dialogue on innovative theories and practices in the arts, and their inter-relationships with society. ISSN: $1833-1866$

htto://wum.Arts-Journal.com

International Journal of the Book

Explores the past, present and future of books, publishing, libraries, information, literacy and learning in: the information society. ISSN: 1447-9567

http://www.Book-Journal.com

Design Principles and Practices: An International Journal

Examines the meaning and purpose of 'design' while also speaking in grounded ways about the task of design and the use of designed artefacts and processes. ISSN: 1833-1874

htto://www.Design-Joumal.com

International Journal of Diversity in Organisations, Communities and Nations

Provides a forum for discussion and builds a body of knowledge on the forms and dynamics of difference and diversity. ISSN: $1447-9583$

hlttp://www.Diversity-Journal.com

International Journal of Environmental, Cultural, Economic and Social Sustainability

Draws from the various fields and perspectives through which we can address fundamental questions of sustainability. ISSN: 1832-2077

http://muw. Sustainability-Journal.com

Global Studies Journal

Maps and interprets new trends and patterns in globalization. ISSN 1835-4432 http://www. GlobalStudiesJournal.com

International Journal of the Humanities

Discusses the role of the humanities in contemplating the future and the human, in an era otherwise dominated by scientific, technical and economic rationalisms. ISSN: 1447-9559

http://www. Humanities-Joumal.com

International Journal of the Inclusive Museum

Addresses the key question: How can the institution of the museum become more inclusive? ISSN 1835-2014 http://www.Museum-Journal.com

International Journal of Interdisciplinary Social Sciences

Discusses disciplinary and interdisciplinary approaches to knowledge creation within and across the various social sciences and between the social, natural and applied sciences.

ISSN: 1833-1882

http://www.Socialsciences-Joumal.com

International Journal of Knowledge, Culture and Change Management

Creates a space for discussion of the nature and future of organisations, in all their forms and manifestations. ISSN: $1447-9575$

http://unw. Management-Journal,com

International Journal of Learning

Sets out to foster inquiry, invite dialogue and build a body of knowledge on the nature and future of learning. ISSN: 1447-9540

http://www.Learning-Journal.com

International Journal of Technology, Knowledge and Society

Focuses on a range of critically important themes in the various fields that address the complex and subtle relationships between technology, knowledge and society. ISSN: 1832-3669 hitp://www. Technology-Journalicom

Journal of the World Universities Forum

Explores the meaning and purpose of the academy in times of striking social transformation. ISSN 1835-2030

Kítp://www. Universities-Journal.com

\section{FOR SUBSCRIPTION INFORMATION, PLEASE CONTACT subscriptions@commonground.com.au}

